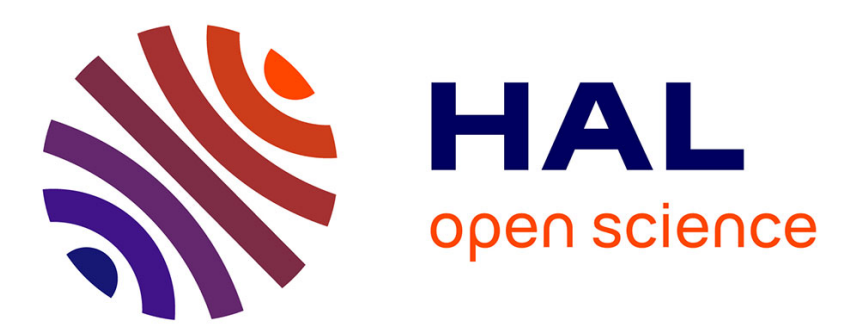

\title{
Everolimus and Sirolimus antagonize Tacrolimus based calcineurin inhibition via competition for FK-binding protein 12
}

Huub H. van Rossum, Fred P.H.T.M. Romijn, Nico P.M. Smit, Johan W. de Fijter, Johannes van Pelt

\section{To cite this version:}

Huub H. van Rossum, Fred P.H.T.M. Romijn, Nico P.M. Smit, Johan W. de Fijter, Johannes van Pelt. Everolimus and Sirolimus antagonize Tacrolimus based calcineurin inhibition via competition for FKbinding protein 12. Biochemical Pharmacology, 2009, 77 (7), pp.1206. 10.1016/j.bcp.2008.12.009 . hal-00493479

\section{HAL Id: hal-00493479 \\ https://hal.science/hal-00493479}

Submitted on 19 Jun 2010

HAL is a multi-disciplinary open access archive for the deposit and dissemination of scientific research documents, whether they are published or not. The documents may come from teaching and research institutions in France or abroad, or from public or private research centers.
L'archive ouverte pluridisciplinaire $\mathbf{H A L}$, est destinée au dépôt et à la diffusion de documents scientifiques de niveau recherche, publiés ou non, émanant des établissements d'enseignement et de recherche français ou étrangers, des laboratoires publics ou privés. 


\section{Accepted Manuscript}

Title: Everolimus and Sirolimus antagonize Tacrolimus based calcineurin inhibition via competition for FK-binding protein 12

Authors: Huub H. van Rossum, Fred P.H.T.M. Romijn, Nico P.M. Smit, Johan W. de Fijter, Johannes van Pelt

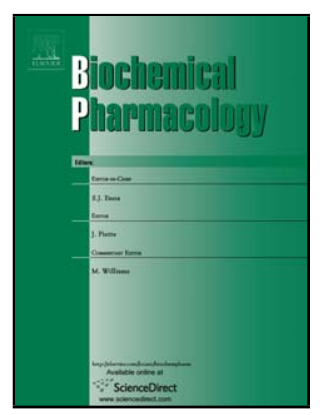

PII: S0006-2952(08)00900-3

DOI: doi:10.1016/j.bcp.2008.12.009

Reference: BCP 10045

To appear in: $\quad B C P$

Received date: $\quad 23-10-2008$

Revised date: $\quad 15-12-2008$

Accepted date: $\quad 16-12-2008$

Please cite this article as: van Rossum HH, Romijn FPHTM, Smit NPM, de Fijter JW, van Pelt J, Everolimus and Sirolimus antagonize Tacrolimus based calcineurin inhibition via competition for FK-binding protein 12, Biochemical Pharmacology (2008), doi:10.1016/j.bcp.2008.12.009

This is a PDF file of an unedited manuscript that has been accepted for publication. As a service to our customers we are providing this early version of the manuscript. The manuscript will undergo copyediting, typesetting, and review of the resulting proof before it is published in its final form. Please note that during the production process errors may be discovered which could affect the content, and all legal disclaimers that apply to the journal pertain. 


\title{
Everolimus and Sirolimus antagonize Tacrolimus based calcineurin
} inhibition via competition for FK-binding protein 12

\author{
Huub H. van Rossum ${ }^{1, *}$, Fred P.H.T.M. Romijn ${ }^{1}$, Nico P.M. Smit ${ }^{1}$, Johan W. de Fijter ${ }^{2}$, \\ Johannes van Pelt ${ }^{1}$ \\ Departments of Clinical Chemistry ${ }^{1}$ and Nephrology ${ }^{2}$ of the Leiden University Medical \\ Center, The Netherlands
}

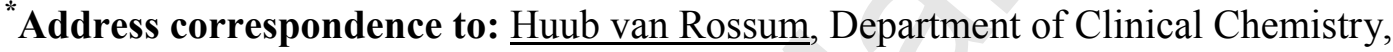
Leiden University Medical Center, Albinusdreef 2, Leiden 2333 ZA, The Netherlands. Tel. +31715262208. Fax. +31715266753. E-mail: h.rossum@lumc.nl
\end{abstract}

\author{
Journal: Biochemical Pharmacology \\ Category: inflammation and immunopharmacology
}

\begin{abstract}
Abbreviations: CN, calcineurin; TRL, tacrolimus; mTOR, mammalian target of rapamycin; MTIs, mTOR inhibitors; FKBP, FK506-binding protein; PBMCs, peripheral blood mononuclear cells; CsA, cyclosporin A; SRL, sirolimus; EVL, everolimus; PHA, phytohemagglutinin; PMA, phorbol-12-myristate-13-acetate; RPMI, roswell park memorial institute medium; iFCS, heat inactivated fetal calf serum; $\mathrm{IC}_{50}$, half maximal inhibition concentration; CI, confidence interval; $\mathrm{E}_{\max }$, maximal drug effect; IL, interleukin; SEM, standard error of the mean
\end{abstract}




\section{Abstract}

The calcineurin inhibitors cyclosporin A and tacrolimus and the inhibitors of the mTOR, sirolimus and everolimus bind immunophilins that are required for their immunosuppressive action. In contrast to cyclosporin A, tacrolimus and the mTOR inhibitors (MTIs) share common immunophilins, the FK506-binding proteins (FKBPs). We investigated the immunosuppressive interactions of MTIs on tacrolimus based immune suppression, since insights in immunological drug-drug interactions can be very relevant for optimization of immunosuppressive regimens in allograft transplantation medicine. Isolated peripheral blood mononuclear cells from healthy volunteers were incubated with combinations of MTIs and calcineurin inhibitors and when monitored for calcineurin activity and IL-2 excretion after mitogen stimulation, tacrolimus $\mathrm{IC}_{50}$ concentrations shifted to higher concentrations in the presence of MTIs. This antagonism was absent for cyclosporin A, reproducible for 10 healthy volunteers $(\mathrm{p}<0.001)$ and stronger for sirolimus than for everolimus. When cell lysate was treated with and without MTI, tacrolimus and FKBP12, FKBP12 could increase calcineurin inhibition by tacrolimus and reverse the MTI antagonism for both MTIs. These results demonstrate that FKBP12 can be rate limiting for calcineurin inhibition at high tacrolimus concentrations and that the antagonism of sirolimus and everolimus on tacrolimus based immune suppression is mediated via saturation of FKBP12. 
1

2 


\section{Introduction}

After organ transplantation, immune suppression to prevent allograft rejection is crucial for successful graft survival. Several immunosuppressive agents, such as the calcineurin $(\mathrm{CN})$ inhibitors tacrolimus (TRL) or cyclosporin A (CsA) and the mammalian target of rapamycin (mTOR) inhibitors sirolimus (SRL) or its derivative everolimus (EVL), are used and combinational therapies are applied to achieve optimal immunosuppressive effect and reduce individual drug toxicity [1]. CsA and TRL inhibit CN, a calcium/calmodulin dependent serine/threonine protein phosphatase that plays an important role in mediating $\mathrm{T}$ cell receptor stimuli into cytokine (IL-2, IFN $\gamma$ ) transcription. SRL and EVL inhibit mTOR, a kinase with a key function in cell cycle progression [1,2]. Both classes of drugs inhibit enzyme activity only after binding to specific intracellular binding proteins, so called immunophilins $[3,4]$. CsA binds selectively to the cyclophilin class of immunophilins that are cytosolic peptidyl-prolyl isomerases, while TRL and the mTOR inhibitors (MTIs) bind to the FK506-binding proteins (FKBP) that also exert peptidyl-prolyl isomerase activity [3]. SRL, EVL and TRL bind similar FKBPs [5,6], while distinct and selective inhibition of respectively mTOR and $\mathrm{CN}$ is observed [7]. Since similar FKBPs are required for successful CN inhibition by TRL and mTOR inhibition by SRL or EVL, pharmacological drug-drug interactions have been investigated by several groups. Dumont et al. has shown that SRL and TRL are reciprocal antagonists $[5,8]$, while others have demonstrated immunosuppressive synergism of these drugs $[9,10]$. In clinical practice, pharmacokinetic drug-drug interactions on metabolic and drugtransporter proteins are therapeutically avoided or adjusted for by therapeutic drug 
monitoring. When drug-drug interactions occur on the pharmacologic level and thus inhibit each others effectiveness, concentration measurement becomes less relevant since it is unable to detect this interaction [10]. In addition, combinations of immunosuppressive drugs might be associated with immunosuppressive synergism [11]. Pharmacodynamic monitoring strategies that can detect these interactions may prove to be useful to further optimize immunosuppressive regimen [12].

In this respect we studied the interaction of EVL and SRL on TRL based immunosuppression in peripheral blood mononuclear cells (PBMCs) isolated from healthy individuals. Pharmacological interaction was investigated by measurement of $\mathrm{CN}$ enzyme activity. For immunological monitoring, the IL-2 downstream product of CN was used. 


\section{Materials and Methods}

\subsection{Materials}

The following materials and reagents were used: Buffy coats were purchased from Sanquin (Amsterdam, NL). RPMI 1640, heat inactivated fetal calf serum (iFCS), penicillin/streptomycin, phytohemagglutinin (PHA) and IL-2 EASIA kit from Invitrogen (Carlsbad, CA), NP-40, soybean trypsin inhibitor, cyclosporin A, tacrolimus, sirolimus (rapamycin), FKBP12 and phorbol-12-myristate-13-acetate (PMA) from Sigma-Aldrich (Steinheim, Germany). Phenylmethylsulfonyl fluoride from MERCK (Darmstadt, Germany), leupeptin from Roche (Basel, Switzerland), aprotinin from Bayer (Leverkusen, Germany), phosphate standard concentrate and everolimus from Fluka (Buchs, Switzerland) and the malachite green calcineurin activity assay kit from Biomol (Plymouth Meeting, PA). All other chemicals and reagents were of the highest available grade.

\subsection{Immunosuppressants}

The immunosuppressants CsA (MW 1203), TRL (MW 804), EVL (MW 958) and SRL (MW 914) were dissolved in ethanol and serial diluted in ethanol. These immunosuppressant stock solutions were diluted in the experiments resulting in final CsA, EVL and SRL concentrations of $0.025,0.25,2.5,25,250$ and $2500 \mu \mathrm{g} / \mathrm{L}$ and final TRL concentrations of $0.00625,0.0625,0.625,6.25,62.5$ and $625 \mu \mathrm{g} / \mathrm{L}$. Final ethanol concentrations were $0.25 \%$ for single immunosuppressant experiments and $0.5 \%$ for the interaction experiments. For the CsA inhibition curve in figure 2, CsA ranged from 0.1 to 
$3600 \mu \mathrm{g} / \mathrm{L}$ with final ethanol concentrations of $1 \%$. The ethanol concentrations resulted in a 5\% increase in $\mathrm{CN}$ activity when compared to an ethanol blank ( $\mathrm{n}=4, \mathrm{p}=0.04)$.

\subsection{PBMC isolation and cell culture}

Peripheral blood mononuclear cell (PBMC) fraction of healthy volunteer blood was isolated from buffy coats by ficoll density gradient centrifugation. Remaining of erythrocytes and thrombocytes were lysed and washed out by $\mathrm{NH}_{4} \mathrm{Cl}$ lysis buffer $(8.4 \mathrm{~g} / \mathrm{L}$ $\mathrm{NH}_{4} \mathrm{Cl}, 1.0 \mathrm{~g} / \mathrm{L} \mathrm{KHCO}_{3}, \mathrm{pH} 7.3$ ) and resuspended in phosphate buffered saline (PBS, 154 $\mathrm{mmol} / \mathrm{L} \mathrm{NaCl}, 1.4 \mathrm{mmol} / \mathrm{L}$ phosphate $\mathrm{pH} 7.5$ ) for cell count on a Sysmex XE2100. Cells were centrifuged $\left(10 \mathrm{~min} ., 350 \mathrm{~g}, 4^{\circ} \mathrm{C}\right)$ and resuspended at a concentration of $2 \cdot 10^{6}$ cells $/ \mathrm{mL}$ in RPMI 1640 cell culture containing $10 \% \mathrm{iFCS}, 100 \mathrm{U} / \mathrm{mL}$ penicillin and 100 $\mu \mathrm{g} / \mathrm{mL}$ streptomycin.

For $\mathrm{CN}$ activity measurement, cells were incubated for $1 \mathrm{hr}$ at $37^{\circ} \mathrm{C}$ with immunosuppressant(s). After incubation, samples were centrifuged $\left(10 \mathrm{~min} ., 350 \mathrm{~g}, 4^{\circ} \mathrm{C}\right)$ and cell pellets were washed once with $400 \mu \mathrm{L}$ HEPES buffered saline $(9.0 \mathrm{~g} / \mathrm{L} \mathrm{NaCl}, 10$ $\mathrm{mmol} / \mathrm{L}$ Hepes $\mathrm{pH} 7.5)$, resuspended in $400 \mu \mathrm{L}$ lysis buffer ( $50 \mathrm{mmol} / \mathrm{L}$ Tris $\mathrm{HCl} \mathrm{pH}$ 7.7, $1.0 \mathrm{mmol} / \mathrm{L}$ dithiothreitol, $5.0 \mathrm{mmol} / \mathrm{L}$ ascorbic acid, $0.02 \%$ (v/v) NP-40, $50 \mathrm{mg} / \mathrm{L}$ soybean trypsin inhibitor, $50 \mathrm{mg} / \mathrm{L}$ phenylmethylsulphonyl fluoride, $5.0 \mathrm{mg} / \mathrm{L}$ leupeptin and 5.0 $\mathrm{mg} / \mathrm{L}$ aprotinin) and lysed by 3 freeze thaw cycles (liquid $\mathrm{N}_{2} / 30^{\circ} \mathrm{C}$ ). Cell debris was centrifuged (10 min., $10000 \mathrm{~g}, 4^{\circ} \mathrm{C}$ ) and supernatants were snap frozen in liquid $\mathrm{N}_{2}$ before storage at $-80^{\circ} \mathrm{C}$ till $\mathrm{CN}$ activity measurement [13].

For IL-2 excretion measurement, cells were stimulated by PHA/PMA 1 hour after incubation with immunosuppressant(s), and incubated overnight at $37^{\circ} \mathrm{C}$ in a humidified 
environment $\left(5 \%, \mathrm{CO}_{2}\right)$. PMA stock solution was 4000 times diluted in cell cultures resulting in a final PMA and DMSO concentration of respectively $5.3 \mathrm{nM}$ and $0.025 \%$, and PHA was 100 times diluted according to manufacturers' protocol. The next day, cells were centrifuged $\left(10 \mathrm{~min} ., 350 \mathrm{~g}, 4{ }^{\circ} \mathrm{C}\right)$ and supernatant was stored at $-20{ }^{\circ} \mathrm{C}$ until IL-2 concentration measurement.

\subsection{Cell lysate experiments}

In order to investigate the role of FKBPs, we isolated PBMCs from buffycoats obtained from healthy volunteers. Untreated PBMCs were lysed as described before and aliquoted lysate was incubated in duplicate $\left(1 \mathrm{hr}, 37^{\circ} \mathrm{C}\right)$ with and without TRL, MTI and FKBP12 resulting in final lysate concentrations of $25 \mu \mathrm{g} / \mathrm{L}$ TRL, $50 \mu \mathrm{g} / \mathrm{L}$ of SRL/EVL and 2000 $\mu \mathrm{g} / \mathrm{L}$ and $10000 \mu \mathrm{g} / \mathrm{L}$ of extra FKBP12. At these concentrations the molar concentrations of the MTIs, TRL and FKBP12 were of the same order of magnitude. Directly after incubation $\mathrm{CN}$ activity was determined.

\subsection{Calcineurin assay}

Calcineurin phosphatase activity was measured as described before [13]. In brief, $\mathrm{CN}$ phosphatase was quantified by measurement of the dephosphorylation of the phosphorylated RII substrate in the presence of okadaic acid. $15 \mu \mathrm{L}$ of sample lysis was added to $40 \mu \mathrm{L}$ of assay buffer $(0.313 \mu \mathrm{mol} / \mathrm{L}$ calmodulin, $0.375 \mathrm{mmol} / \mathrm{L}$ RII phosphopeptide substrate, $75 \mathrm{mmol} / \mathrm{L}$ Tris $\mathrm{pH} 7.5,150 \mathrm{mmol} / \mathrm{L} \mathrm{NaCl}, 9 \mathrm{mmol} / \mathrm{L} \mathrm{MgCl}_{2}$, $0.75 \mathrm{mmol} / \mathrm{L}$ dithiothreitol, $0.0375 \% \mathrm{NP}-40,0.625 \mu \mathrm{mol} / \mathrm{L}$ okadaic acid, $0.75 \mathrm{mmol} / \mathrm{L}$ $\mathrm{CaCl}_{2}$ and $5 \mathrm{mmol} / \mathrm{L}$ ascorbic acid) and substrate blanks were used to correct for 
background absorbance. The assay was run for $30 \mathrm{~min}$. at $30^{\circ} \mathrm{C}$ and stopped by addition of $100 \mu \mathrm{L}$ of malachite green reagent. Colour was developed the next $50 \mathrm{~min}$. before absorbance measurement at $620 \mathrm{~nm}$, and phosphate was quantified by means of a $0-5 \mathrm{nmol}$ calibration curve.

\subsection{Cytokine concentration measurement}

IL-2 concentrations were determined with the EASIA kit (Invitrogen) and performed according to manufacturers' protocol.

\subsection{Data analysis and statistics}

Values are presented as mean of duplicate and blank experiments were performed in quadruple. $\mathrm{CN}$ activity and IL-2 concentrations were expressed as \% of blank measurement in order to remove inter-individual variation in absolute CN activity and IL-2 excretion.

$\mathrm{CN}$ inhibition curves and IL-2 cytokine inhibition curves were fitted by sigmoidal doseresponse curves using GraphPad software and $\mathrm{IC}_{50}$ concentrations, $\mathrm{E}_{\max }$ values and $95 \%$ confidence intervals (CI) were obtained from these regression analysis. Student t-tests were used to test significance and statistical significance was defined as $\mathrm{p}<0.05$. 


\section{Results}

\subsection{IL-2 inhibition by TRL and CsA in the presence of EVL and SRL}

To gain insights whether and under which conditions the immunological interaction between the MTIs and TRL occurred, we first measured the effect of the MTIs on IL-2 inhibition by TRL. PBMCs isolated from healthy volunteers were stimulated using PHA/PMA and IL-2 excretion was measured in the presence of TRL or CsA and various concentrations of EVL or SRL. The results of these experiments are shown in figure 1 and the obtained $\mathrm{IC}_{50}$ values of CsA and TRL in the presence of various concentrations of EVL and SRL are listed in table 1.

The MTIs inhibited IL-2 excretion in the PHA/PMA stimulated PBMCs themselves at the concentration range used and this inhibition increased with increasing concentrations of MTI, though no clear sigmoidal concentration response relationship was visible as well as no inhibition of total IL-2 excretion. When high TRL concentrations were used in combination with EVL or SRL, low concentration of the MTIs did not significantly effect IL-2 inhibition by TRL. However at higher concentrations $(250 \mu \mathrm{g} / \mathrm{L})$, significant shifts in IL-2 IC $_{50}$ values were observed. MTI concentrations of $25 \mu \mathrm{g} / \mathrm{L}$ and higher reversed IL-2 inhibition by TRL though the occurrence and magnitude of this effect is also dependent on the TRL concentration and seems to be less for EVL when compared to SRL (figure 1A and $1 \mathrm{~B})$. No increasing $\mathrm{IC}_{50}$ values and significant differences in $\mathrm{IC}_{50}$ values were observed when CsA was used in combination with EVL and SRL (figure 1C and 1D).

\subsection{CN inhibition by CNIs, MTIs and combinations thereof}


To further investigate the origin of the observed IL-2 antagonism, we measured calcineurin activity that is the pharmacological target enzyme of TRL. First, the individual effect of the immunosuppressants on $\mathrm{CN}$ activity was investigated and therefore $\mathrm{CN}$ inhibition curves were determined for CsA, TRL, EVL and SRL. The data in figure 2 shows that SRL and EVL do not inhibit CN activity, while for TRL and CsA a clear dose-response curve was found with an $\mathrm{IC}_{50}$ value of $1.0 \mu \mathrm{g} / \mathrm{L}(0.51-2.1 \mu \mathrm{g} / \mathrm{L}, 95 \% \mathrm{CI})$ and an $\mathrm{E}_{\max }$ of $53 \%$ (48 $58 \%, 95 \% \mathrm{CI})$ for $\mathrm{TRL}$ and an $\mathrm{IC}_{50}$ value of $14 \mu \mathrm{g} / \mathrm{L}(9.6-21 \mu \mathrm{g} / \mathrm{L}, 95 \% \mathrm{CI})$ and an $\mathrm{E}_{\max }$ of $31 \%(26-36 \%, 95 \% \mathrm{CI})$ for CsA.

Next, we incubated five concentrations of TRL $(0.0625-625 \mu \mathrm{g} / \mathrm{L})$ and a TRL blank, each in combination with five concentrations $(0.25-2500 \mu \mathrm{g} / \mathrm{L})$ and a blank of either EVL or SRL. As control experiment TRL was replaced by CsA $(0.25-2500 \mu \mathrm{g} / \mathrm{L})$. The obtained $\mathrm{CN}$ inhibition curves are shown in figure 3 and the calculated $\mathrm{IC}_{50}$ concentrations for TRL and CsA in the presence of various concentrations of EVL and SRL are listed in table 2. A concentration dependent effect of EVL and SRL on CN inhibition by TRL was observed and significant higher TRL IC 50 values were found when $25 \mu \mathrm{g} / \mathrm{L}$ SRL and $250 \mu \mathrm{g} / \mathrm{L}$ EVL or higher, were present in culture medium (figure 3A and 3B). This pattern was not detected for the $\mathrm{CsA} \mathrm{CN}$ inhibition curves; here no differences in $\mathrm{IC}_{50}$ values were observed by increasing concentration of MTIs (figure 3C and 3D).

\subsection{Antagonism of MTIs on TRL based immune suppression in 10 healthy volunteers To determine whether the TRL/MTI interactions are reproducible for other individuals we investigated the interaction on PBMCs isolated from 10 healthy volunteers.}


For reproduction of the immunological antagonism we reproduced the experiment for 10 healthy volunteers and treated the PBMCs with $0.625 \mu \mathrm{g} / \mathrm{L}$ TRL and $25 \mu \mathrm{g} / \mathrm{L}$ of EVL or SRL, concentrations that previously (figure 1) showed to be characteristic for the interaction. The results are shown in figure 4.

All three drugs inhibited IL-2 excretion in our cell culture system, though TRL caused a larger inhibition than SRL $(p=0.001)$ and EVL $(p=0.002)$ that partially inhibited the IL-2 excretion in these concentrations. When combinations of TRL and MTIs were tested, SRL significantly reversed IL-2 excretion inhibition by TRL $(\mathrm{p}=0.004)$, while for EVL no difference in IL-2 levels was found $(\mathrm{p}=0.53)$. The IL- 2 concentrations observed for the EVL/TRL combination was also significant lower when compared to the combination of $\mathrm{SRL} / \mathrm{TRL}(\mathrm{p}=0.01)$.

Next, we determined CN activity in the presence/absence of TRL $(6.25 \mu \mathrm{g} / \mathrm{L})$ and/or EVL/SRL $(25 \mu \mathrm{g} / \mathrm{L})$, concentrations that were previously illustrative for the interaction (figure 3).

Here no CN inhibition was found for SRL and EVL. TRL caused a mean CN inhibition of $44 \% \pm 11 \%$ (SD) in the PBMC fractions isolated from these individuals. When MTIs were co-incubated with TRL in the culture medium, $\mathrm{CN}$ inhibition by TRL was partially lost and final mean inhibition in the presence of SRL and EVL was $18 \% \pm 14 \%$ and $26 \% \pm 10 \%$, respectively. Both were significant lower $(\mathrm{p}<0.001)$ when compared to TRL alone. Antagonism of SRL on TRL mediated CN inhibition was significantly larger than that of EVL for these concentrations $(\mathrm{p}=0.01)$.

\subsection{Role of FKBPs}


To investigate whether the mechanism of antagonism between both mTOR inhibitors and TRL was mediated via competition for saturated FKBP binding sites, we prepared PBMC lysate from untreated cells of 4 healthy volunteers in duplicate and incubated $\left(1 \mathrm{hr}, 37^{\circ} \mathrm{C}\right)$ these with and without mTOR inhibitor, TRL and FKBP12. CN activity was determined directly after incubation. The results of these experiments are shown in figure 5. In this test system no inhibition of $\mathrm{CN}$ was found by the MTIs, FKBP12 and combinations thereof (data not shown). Inhibition by TRL in cell lysate was observed though it was much smaller $( \pm 10 \%)$ compared to the cell systems. Since the addition of $2000 \mu \mathrm{g} / \mathrm{L}$ FKBP12 increased TRL inhibition $( \pm 35 \%, \mathrm{p}<0.001)$ it seemed that the FKBP12 pool from the intracellular compartment was diluted in the cell lysate, limiting CN inhibition by TRL. Addition of SRL to TRL reduced TRL inhibition of $\mathrm{CN}(\mathrm{p}=0.005)$, while for EVL antagonism under these conditions could not be detected $(\mathrm{p}=0.7)$. In the presence of 2000 $\mu \mathrm{g} / \mathrm{L}$ FKBP12 antagonism for both SRL and EVL was found (for both $\mathrm{p}<0.001$ ) and when $10000 \mu \mathrm{g} / \mathrm{L}$ FKBP12 was used, antagonism of both MTIs was no longer observed. 


\section{Discussion}

In transplant recipients, multiple immunosuppressive agents are normally used in order to optimally prevent acute rejection episodes and to reduce the side effects of the individual drugs [1]. The CNI and MTI class of drugs require intracellular binding proteins (immunophilins) to exert their immunosuppressive action. TRL binds to its intracellular binding proteins (FKBPs) and especially the $12 \mathrm{kDa}$ protein FKBP12 is considered critical for the immunosuppressive action of TRL [14]. The MTIs SRL and its analog EVL require binding to the same protein though an other immunosuppressive mechanism is observed for these drugs $[6,15]$. Where TRL inhibits $\mathrm{CN}$ and block T-cell receptor induced activation/proliferation of T cells, the mTOR inhibitors inhibit IL-2 induced T-cell proliferation $[7,15]$. In this study, using a $\mathrm{CN}$ assay, we confirmed that $\mathrm{CN}$ enzyme activity is not inhibited by EVL and SRL but selectively by TRL and CsA (figure 2), which is in agreement with previous observations.

In studies by Dumont et al., reciprocal antagonism was observed for SRL and TRL which was explained by the use of similar intracellular binding sites of the drugs $[5,8]$. Here we show that both SRL and EVL antagonize TRL mediated CN inhibition and TRL inhibition of IL-2 excretion in PHA/PMA stimulated PBMCs, an effect which is not observed for the CNI CsA. In addition, we show that the antagonism between MTIs and TRL in cell lysate is reversed by the addition of excess of FKBP12 $(10000 \mu \mathrm{g} / \mathrm{L})$, indicating that the antagonism is mediated via this protein.

The in vitro antagonism observed in our cellular system is significant starting at SRL concentrations of $25 \mu \mathrm{g} / \mathrm{L}$ for $\mathrm{CN}$ activity and $250 \mu \mathrm{g} / \mathrm{L}$ for IL-2 excretion and at EVL 
concentrations of $250 \mu \mathrm{g} / \mathrm{L}$ for both $\mathrm{CN}$ inhibition and IL-2 excretion inhibition by TRL. These relative high concentrations of MTIs in combination with TRL seem to saturate FKBP binding sites that are required for $\mathrm{CN}$ inhibition by TRL. Competition between the MTIs and TRL for these binding sites is clearly illustrated by the IL-2 interaction experiments in figure 1 . Here it is shown that $0.625 \mu \mathrm{g} / \mathrm{L}$ TRL itself inhibits IL-2 excretion, but when increasing concentrations of SRL are introduced, above a certain threshold ( 25 $\mu \mathrm{g} / \mathrm{L}$ SRL), IL-2 inhibition by TRL is lost and the IL-2 response is more comparable to the $25 \mu \mathrm{g} / \mathrm{L}$ SRL response itself.

The MTIs themselves reduce IL-2 excretion in our cell culture system, without showing a clear sigmoidal concentration-response relationship. This effect is probably best explained to be indirect and mediated through inhibition of proliferation/activation of IL-2 producing cells. In our system the lowest MTIs concentrations used already significantly decreased IL-2 excretion. Under these conditions of low MTI concentration, immunosuppressive additivity or even synergism could be very well achieved in patients in combination protocols with CsA, but also TRL; although MTIs are mechanistically antagonists of TRL, antagonism only occurs at saturating conditions for FKBP. Immunosuppressive synergy has been demonstrated for SRL/TRL and SRL/CsA combinations on lymphocyte proliferation and lymphocyte activation markers [10]. $25 \mu \mathrm{g} / \mathrm{L}$ of both EVL and SRL partially reversed CN inhibition by $6.25 \mu \mathrm{g} / \mathrm{L}$ TRL though the interference by SRL was significant larger when compared to EVL in 10 healthy volunteers. In addition, only SRL could significantly reverse IL-2 inhibition by $0.625 \mu \mathrm{g} / \mathrm{L}$ TRL. These results indicate relevant differences between both MTIs that could be explained by the weaker binding of EVL to FKBP12 [6]. 
Kung and Halloran showed that at high concentrations of CNIs, immunophilins limit CN inhibition for both CsA and TRL [16]. It is however not known whether this is relevant for CNI treated patients. When using combination immunosuppressant therapy of both MTI and TRL, saturation of FKBPs and thus pharmacological drug-drug interaction is even more likely and this interaction could therefore be clinically relevant. The MTI concentrations for which TRL antagonism was observed $(25 \mu \mathrm{g} / \mathrm{L})$ are of the same magnitude of MTI blood concentrations in allograft recipients treated with these drugs [17]. In addition, also the TRL concentrations at which the interference was observed are found in allograft recipients treated with this drug [17]. The drug concentrations that are used in our in vitro model can however not directly be translated to full blood drug concentrations, since drug concentrations from cell culture experiments do not necessarily show similar cellular responses compared to drug concentrations in blood due to the presence of irrelevant binding sites as has been demonstrated for CsA [18]. The true clinical relevance remains therefore unclear.

If $\mathrm{CN}$ inhibition is limited by the immunophilin content in patients receiving CNI, this could be of great importance; higher CNI concentrations are ineffective. Especially early after graft implantation, when the blood concentrations are highest, this might become relevant. Consequently, under condition of immunophilin saturation, inter-individual variation in the content of immunophilins could be of great importance for allowing different maximal $\mathrm{CN}$ inhibitions.

Finally, blood drug concentrations and also intracellular drug concentrations are not able to detect the limitation of $\mathrm{CN}$ inhibition by immunophilins. Only pharmacodynamic strategies 
1

2

are theoretically capable of detecting these. This also holds for detecting the interaction between the MTI and TRL in individuals receiving both drugs.

In conclusion, it is shown that mTOR inhibitors can antagonize TRL and not CsA mediated immunosuppression. FKBP12 that is bound by EVL and SRL, and required for TRL based $\mathrm{CN}$ inhibition is a key mediator; saturation of this protein by high concentrations of MTIs and TRL results in competition for FKBP12. 


\section{References}

[1] Halloran PF. Immunosuppressive drugs for kidney transplantation. New England Journal of Medicine 2004; 351: 2715-29.

[2] Feske S, Giltnane J, Dolmetsch R, Staudt LM, and Rao A. Gene regulation mediated by calcium signals in T lymphocytes. Nature Immunology 2001; 2: 316-24.

[3] Liu J, Farmer JD, Lane WS, Friedman J, Weissman I, and Schreiber SL. Calcineurin Is A Common Target of Cyclophilin-Cyclosporine-A and Fkbp-Fk506 Complexes. Cell 1991; 66: 807-15.

[4] Dumont FJ and Su QX. Mechanism of action of the immunosuppressant rapamycin. Life Sciences 1995; 58: 373-95.

[5] Dumont FJ, Melino MR, Staruch MJ, Koprak SL, Fischer PA, and Sigal NH. The Immunosuppressive Macrolides Fk-506 and Rapamycin Act As Reciprocal Antagonists in Murine T-Cells. Journal of Immunology 1990; 144: 1418-24.

[6] Schuler W, Sedrani R, Cottens S, Haberlin B, Schulz M, Schuurman HJ, Zenke G, Zerwes HG, and Schreier MH. SDZ RAD, a new rapamycin derivative Pharmacological properties in vitro and in vivo. Transplantation 1997; 64: 36-42.

[7] Dumont FJ, Staruch MJ, Koprak SL, Melino MR, and Sigal NH. Distinct Mechanisms of Suppression of Murine T-Cell Activation by the Related Macrolides Fk-506 and Rapamycin. Journal of Immunology 1990; 144: 251-8. 
[8] Dumont FJ, Kastner C, Iacovone F, and Fischer PA. Quantitative and Temporal Analysis of the Cellular Interaction of Fk-506 and Rapamycin in T-Lymphocytes. Journal of Pharmacology and Experimental Therapeutics 1994; 268: 32-41.

[9] Vu MD, Qi S, Xu D, Wu J, Fitzsimmons WE, Sehgal SN, Dumont L, Busque S, Daloze P, and Chen H. Tacrolimus (FK506) and sirolimus (rapamycin) in combination are not antagonistic but produce extended graft survival in cardiac transplantation in the rat. Transplantation 1997; 64: 1853-6.

[10] Barten MJ, Streit F, Boeger M, Dhein S, Tarnok A, Shipkova M, Armstrong VW, Mohr FW, Oellerich M, and Gummert JF. Synergistic effects of sirolimus with cyclosporine and tacrolimus: Analysis of immunosuppression on lymphocyte proliferation and activation in rat whole blood. Transplantation 2004; 77: 1154-62.

[11] Oellerich M, Barten MJ, and Armstrong VW. Biomarkers - The link between therapeutic drug monitoring and pharmacodynamics. Therapeutic Drug Monitoring 2006; $28: 35-8$.

[12] Burkhart C, Heusser C, Morris RE, Raulf F, Weckbecker G, Weitz-Schmidt G, and Welzenbach K. Pharmacodynamics in the development of new immunosuppressive drugs. Therapeutic Drug Monitoring 2004; 26: 588-92.

[13] Sellar KJ, van Rossum HH, Romijn FPHT, Smit NPM, de Fijter JW, and van Pelt J. Spectrophotometric assay for calcineurin activity in leukocytes isolated from human blood. Analytical Biochemistry 2006; 358: 104-10. 
[14] Bram RJ, Hung DT, Martin PK, Schreiber SL, and Crabtree GR. Identification of the Immunophilins Capable of Mediating Inhibition of Signal-Transduction by Cyclosporine-A and Fk506 - Roles of Calcineurin Binding and Cellular Location. Molecular and Cellular Biology 1993; 13: 4760-9.

[15] Bierer BE, Mattila PS, Standaert RF, Herzenberg LA, Burakoff SJ, Crabtree G, and Schreiber SL. 2 Distinct Signal Transmission Pathways in T-Lymphocytes Are Inhibited by Complexes Formed Between An Immunophilin and Either Fk506 Or Rapamycin. Proceedings of the National Academy of Sciences of the United States of America 1990; 87: 9231-5.

[16] Kung L and Halloran PF. Immunophilins may limit calcineurin inhibition by cyclosporine and tacrolimus at high drug concentrations. Transplantation 2000; 70: $327-35$.

[17] Oellerich M and Armstrong VW. The role of therapeutic drug monitoring in individualizing immunosuppressive drug therapy: Recent developments. Therapeutic Drug Monitoring 2006; 28: 720-5.

[18] Batiuk TD, Pazderka F, Enns J, DeCastro L, and Halloran PF. Cyclosporine inhibition of leukocyte calcineurin is much less in whole blood than in culture medium. Transplantation 1996; 61: 158-61. 


\section{Legends for figures}

Figure 1. IL-2 inhibition by TRL and CsA in the presence of MTIs. IL-2 inhibition by TRL was determined in the presence of various concentrations of SRL (A) and EVL (B). C and $\mathrm{D}$ show the $\mathrm{CN}$ inhibition by CsA in the presence of the same concentrations of SRL and EVL respectively. Data show the mean of duplicate measurement for one healthy individual.

Figure 2. CN inhibition by CsA, TRL, SRL and EVL. Data are normalized and expressed as \% by dividing through CNI blank measurement (performed in quadruple) and maximum effect was fixed at 100\% for the sigmodial dose-response analysis in Graphpad. Data are presented as mean of duplicate measurement.

Figure 3. CN inhibition by CsA and TRL in the presence of MTIs. CN inhibition by TRL was determined in the presence of SRL (A) and EVL (B). C and D show the CN inhibition by CsA in the presences of the same concentrations of SRL and EVL respectively. Data show the mean of duplicate of one healthy individual and the lines are the $\mathrm{CN}$ inhibition curves of TRL and CsA in the presence of various concentrations of EVL and SRL fitted for sigmodial dose-response curves by Graphpad software. The $\mathrm{IC}_{50}$ values for CsA and TRL obtained from these curves are listed in table 2. Data was normalized by dividing through blank measurement in the absence of CNI and MTI. CNI 0 values were set at $10^{-4} \mu \mathrm{g} / \mathrm{L}$ for the regression analysis. 
Figure 4. MTI antagonism in 10 healthy volunteers. Left: IL-2 excretion after PHA/PMA stimulation for combinations of TRL $(0.625 \mu \mathrm{g} / \mathrm{L}$ TRL) and MTIs (25 $\mu \mathrm{g} / \mathrm{L})$. Right: CN activity in the presence/absence of $6.25 \mu \mathrm{g} / \mathrm{L}$ TRL, and $25 \mu \mathrm{g} / \mathrm{L}$ EVL or SRL. Both were tested on PBMCs isolated from 10 healthy volunteers and data was normalized to remove inter-individual variation in absolute IL-2 excretion and CN activity. Data are presented as mean \pm SEM and statistical significance was tested using paired student t-tests and presented as $* * *$ for $\mathrm{p}<0.001$ and $* *$ for $\mathrm{p}<0.01$

Figure 5. CN activity after FKBP12, TRL and MTI addition to cell lysate. CN activity was determined in PBMC lysate in the presence/absence of TRL, FKBP12 and either SRL or EVL and expressed as \% of blank measurement. Final concentrations were $25 \mu \mathrm{g} / \mathrm{L}$ TRL, $50 \mu \mathrm{g} / \mathrm{L}$ of SRL/EVL and 0, 2000 and $10000 \mu \mathrm{g} / \mathrm{L}$ of FKBP12 was added to cell lysate. Results were obtained from duplicate measurement of 4 healthy volunteers and presented as mean \pm SEM. Statistical analysis were performed between TRL and TRL + SRL or EVL conditions, except when lines indicate otherwise and presented as $* * *$ for $\mathrm{p}<0.001$ and NS for not significant. 
Table 1.

\begin{tabular}{llll}
\hline & [mTOR inhibitor] & Tacrolimus & Cyclosporin A \\
in $\mu \mathrm{g} / \mathrm{L}$ & $\mathrm{IC}_{50}$ in $\mu \mathrm{g} / \mathrm{L}(95 \% \mathrm{CI})$ & $\mathrm{IC}_{50}$ in $\mu \mathrm{g} / \mathrm{L}(95 \% \mathrm{CI})$ \\
\hline Sirolimus & 0 & $\mathbf{0 . 2 0}(0.12-0.33)$ & $\mathbf{8 . 5}(2.6-27)$ \\
& 0.25 & $\mathbf{0 . 1 4}(0.09-0.23)$ & $\mathbf{2 . 7}(1.1-6.7)$ \\
2.5 & $\mathbf{0 . 2 2}(0.11-0.44)$ & $\mathbf{2 . 1}(1.1-4.1)$ \\
25 & $\mathbf{1 . 6}(0.57-4.6)$ & $\mathbf{4 . 7}(2.4-9.2)$ \\
250 & $\mathbf{1 1}(4.8-26)$ & $\mathbf{1 . 2}(0.35-4.1)$ \\
2500 & $\mathbf{1 1 4}(56-234)$ & $\mathbf{0 . 5 9}(0.05-6.8)$ \\
\hline 0 & $\mathbf{0 . 1 5}(0.06-0.36)$ & $\mathbf{9 . 5}(4.7-19)$ \\
25 & $\mathbf{0 . 1 3}(0.05-0.31)$ & $\mathbf{3 . 6}(2.1-6.3)$ \\
250 & $\mathbf{0 . 1 3}(0.05-0.38)$ & $\mathbf{4 . 7}(2.9-7.5)$ \\
25 & $\mathbf{0 . 2 8}(0.14-0.55)$ & $\mathbf{2 . 1}(0.84-5.0)$ \\
& $\mathbf{2 . 6}(1.4-4.6)$ & $\mathbf{5 . 6}(3.1-10)$ \\
& & $\mathbf{1 9 . 0}(0.84-4.9)$ \\
\hline
\end{tabular}

Table 1. IL-2 IC 50 values of TRL and CsA in the presence of various concentrations of SRL and EVL. $\mathrm{IC}_{50}$ values and 95\% Confidence Intervals (CI) were obtained from the sigmoidal concentration-response regressions when the data in figure 1 is presented with the CNI inhibitor on the $\mathrm{x}$-axis and the individual curves are variations in EVL or SRL concentrations. 
Table 2

\begin{tabular}{llll}
\hline & [mTOR inhibitor] & Tacrolimus & Cyclosporin A \\
in $\mu \mathrm{g} / \mathrm{L}$ & $\mathrm{IC}_{50}$ in $\mu \mathrm{g} / \mathrm{L}(95 \% \mathrm{CI})$ & $\mathrm{IC}_{50}$ in $\mu \mathrm{g} / \mathrm{L}(95 \% \mathrm{CI})$ \\
\hline Sirolimus & 0 & $\mathbf{1 . 0}(0.32-3.4)$ & $\mathbf{3 0}(12-74)$ \\
& 0.25 & $\mathbf{1 . 5}(0.69-3.4)$ & $\mathbf{1 3}(7.8-23)$ \\
2.5 & $\mathbf{3 . 8}(1.6-8.8)$ & $\mathbf{3 1}(15-63)$ \\
25 & $\mathbf{1 1}(6.7-18)$ & $\mathbf{2 9}(11-79)$ \\
250 & $\mathbf{1 2 5}(25-620)$ & $\mathbf{1 3}(5.3-31)$ \\
2500 & $\mathbf{2 9 0}\left(0.08-1.1 \cdot 10^{6}\right)$ & $\mathbf{1 6}(8.5-31)$ \\
\hline 0 & $\mathbf{0 . 5 4}(0.15-1.9)$ & $\mathbf{1 4}(5.1-41)$ \\
25 & $\mathbf{0 . 7 0}(0.34-1.4)$ & $\mathbf{7 . 6}(3.7-16)$ \\
25 & $\mathbf{1 . 2}(0.39-3.9)$ & $\mathbf{1 3}(4.0-43)$ \\
250 & $\mathbf{4 . 6}(0.91-23)$ & $\mathbf{1 1}(5.2-23)$ \\
\hline & $\mathbf{2 0}(3.7-104)$ & $\mathbf{7 . 1}(4.0-13)$ \\
& $\mathbf{3 2 0}\left(0.21-5.0 \cdot 10^{5}\right)$ & $\mathbf{1 3}(9.8-17)$ \\
\hline
\end{tabular}

Table 2. CN IC 50 values of TRL and CsA in the presence of various concentrations of SRL and EVL. $\mathrm{IC}_{50}$ values and 95\% Confidence Intervals (CI) were obtained from the sigmoidal concentration-response regressions presented in figure 3 by Graphpad software. 


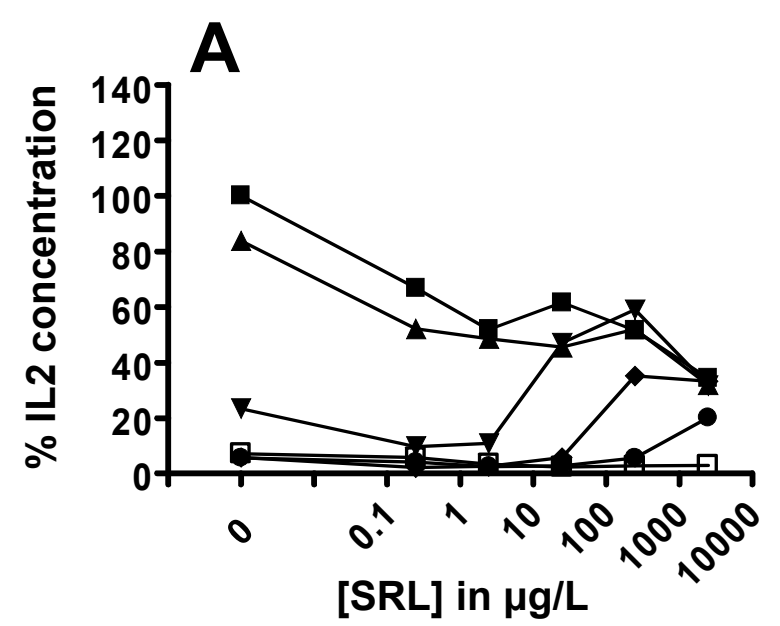

$\rightarrow-0 \mu \mathrm{g} / \mathrm{L} T R L$

$\leftarrow 0.0625 \mu \mathrm{g} / \mathrm{L} \mathrm{TRL}$

$\rightarrow-0.625 \mu \mathrm{g} / \mathrm{L}$ TRL

$\rightarrow-6.25 \mu \mathrm{g} / \mathrm{L}$ TRL

$\bullet-62.5 \mu \mathrm{g} / \mathrm{L}$ TRL

๑ $625 \mu \mathrm{g} / \mathrm{L}$ TRL

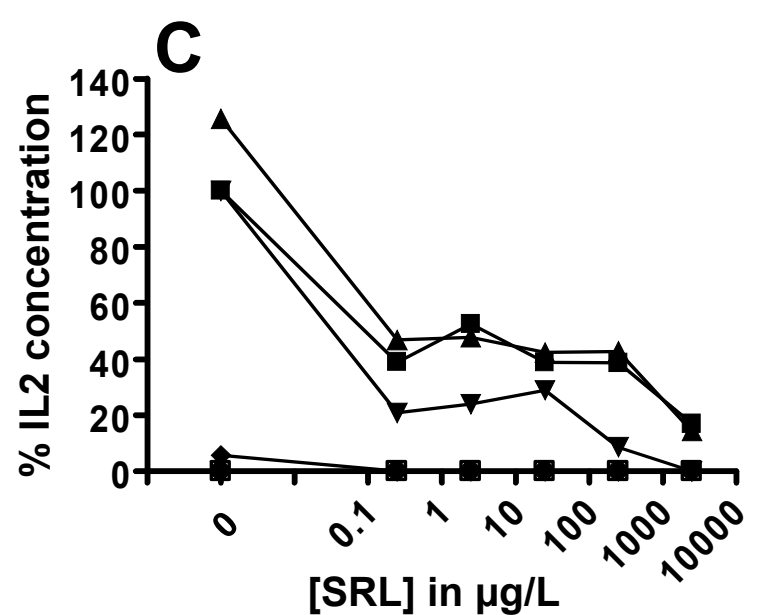

$\rightarrow-0 \mu \mathrm{g} / \mathrm{L} \mathrm{CsA}$

$\leftarrow 0.25 \mu \mathrm{g} / \mathrm{L}$ CsA

$\rightarrow-2.5 \mu \mathrm{g} / \mathrm{L} \mathrm{CsA}$

$\rightarrow-25 \mu \mathrm{g} / \mathrm{L}$ CsA

$\rightarrow 250 \mu \mathrm{g} / \mathrm{L}$ CsA

曰-2500 $\mu \mathrm{g} / \mathrm{L}$ CsA

[SRL] in $\mu \mathrm{g} / \mathrm{L}$

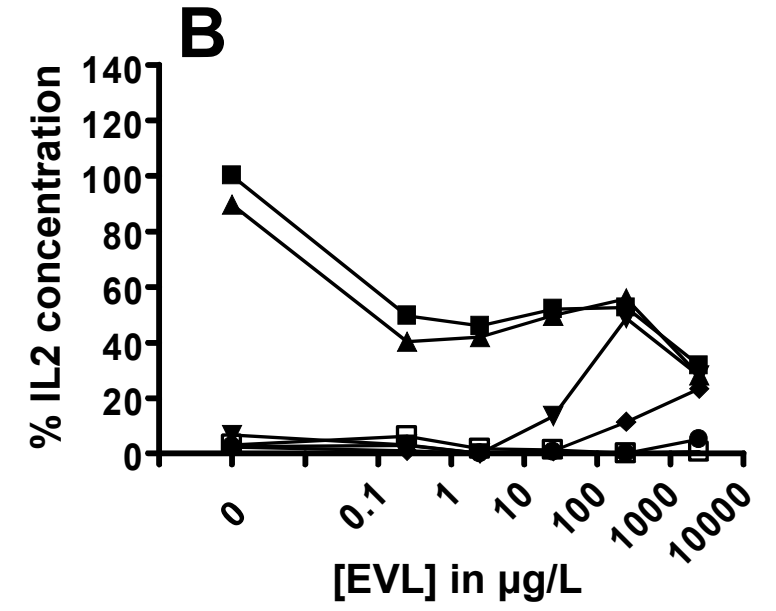

$\rightarrow-0 \mu \mathrm{g} / \mathrm{L} T R L$

$\leftarrow 0.0625 \mu \mathrm{g} / \mathrm{L}$ TRL

$\rightarrow 0.625 \mu \mathrm{g} / \mathrm{L}$ TRL

$\rightarrow-6.25 \mu \mathrm{g} / \mathrm{L}$ TRL

$\rightarrow-62.5 \mu \mathrm{g} / \mathrm{L}$ TRL

๑625 $\mu \mathrm{g} / \mathrm{L}$ TRL

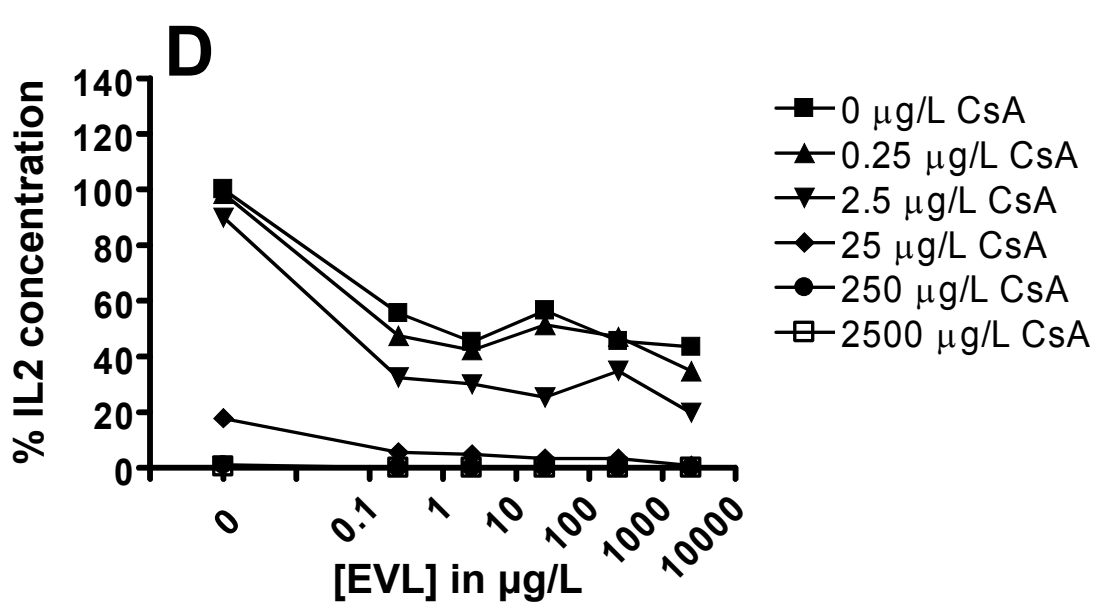




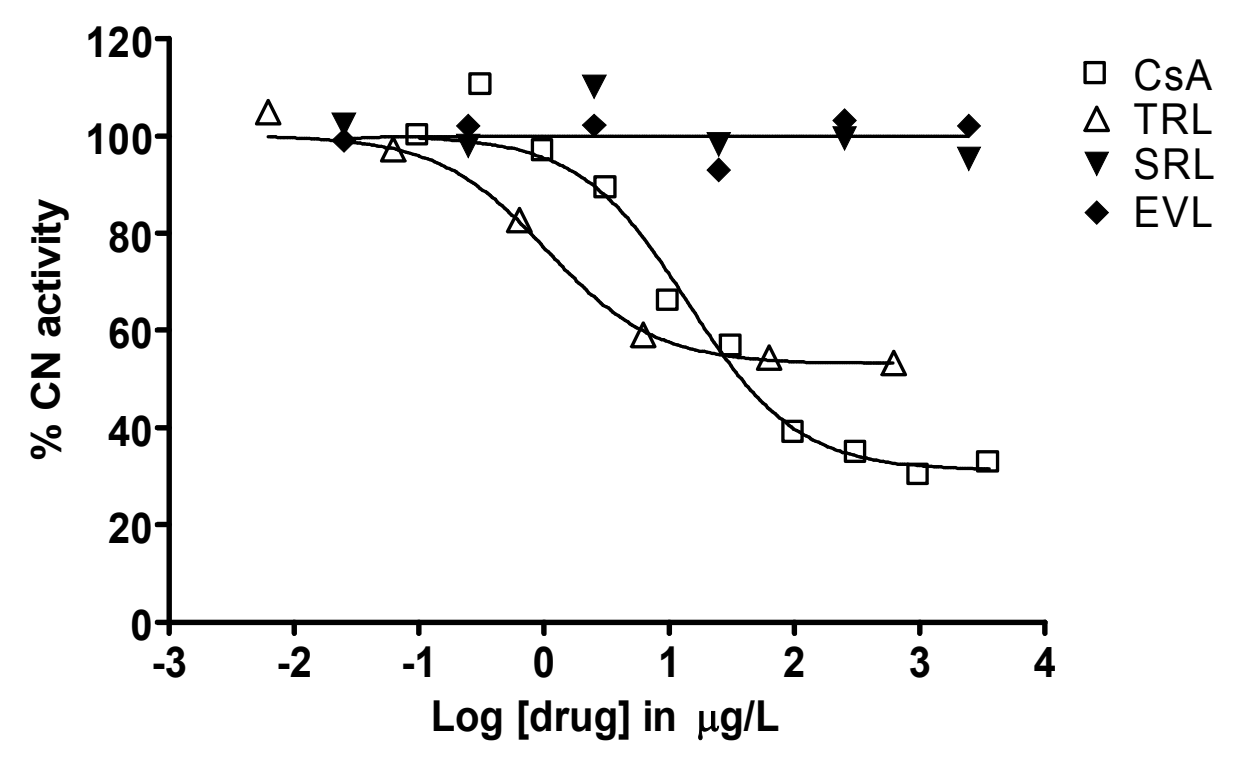




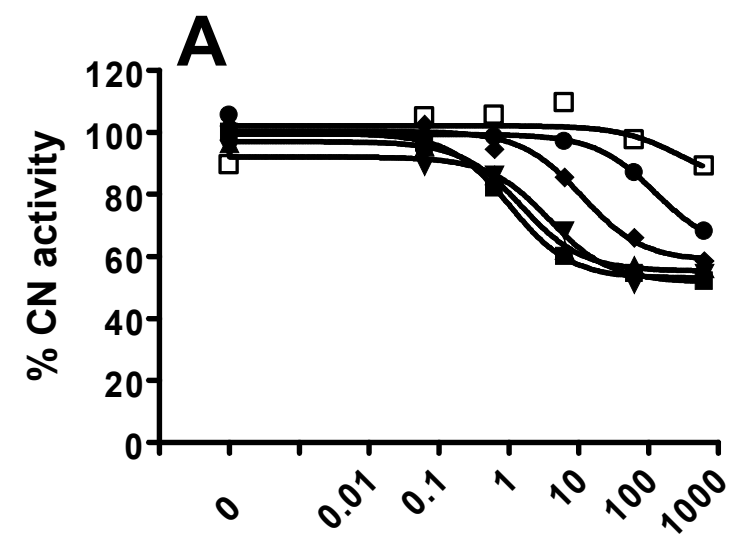

[TRL] in $\mu g / L$

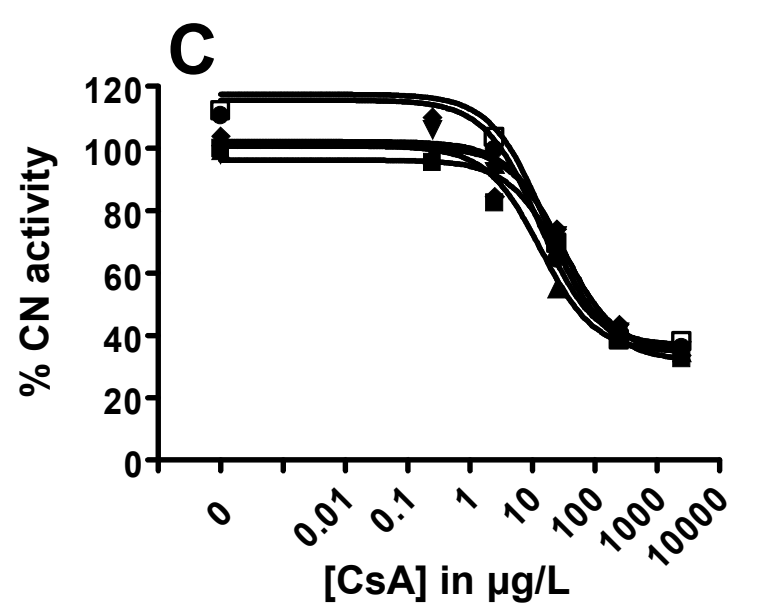

- $0 \mu \mathrm{g} / \mathrm{L} \mathrm{SRL}$

- $0.25 \mu \mathrm{g} / \mathrm{L} \mathrm{SRL}$

> $2.5 \mu \mathrm{g} / \mathrm{L} \mathrm{SRL}$

- $25 \mu \mathrm{g} / \mathrm{L}$ SRL

- $250 \mu \mathrm{g} / \mathrm{L}$ SRL

$2500 \mu \mathrm{g} / \mathrm{L} \mathrm{SRL}$

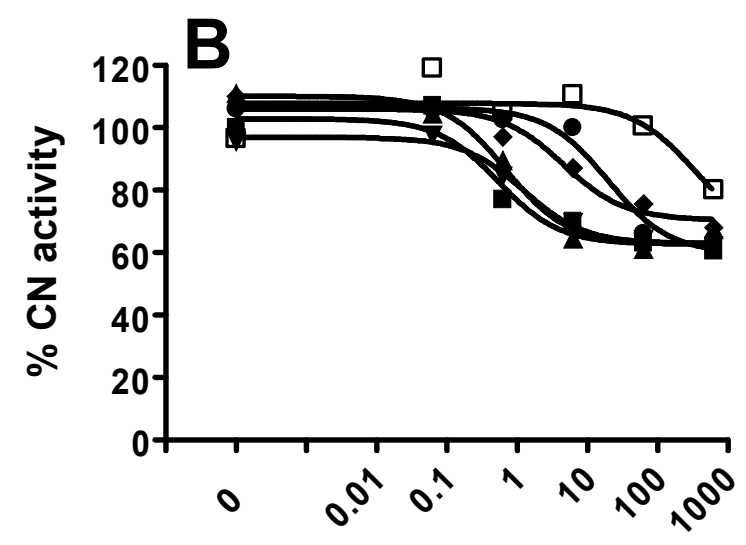

[TRL] in $\mu g / L$

- $0 \mu \mathrm{g} / \mathrm{L} \mathrm{SRL}$

\ $0.25 \mu \mathrm{g} / \mathrm{L} \mathrm{SRL}$

$\checkmark 2.5 \mu \mathrm{g} / \mathrm{L} \mathrm{SRL}$

- $25 \mu \mathrm{g} / \mathrm{L}$ SRL

- $250 \mu \mathrm{g} / \mathrm{L}$ SRL

口 $2500 \mu \mathrm{g} / \mathrm{L} \mathrm{SRL}$

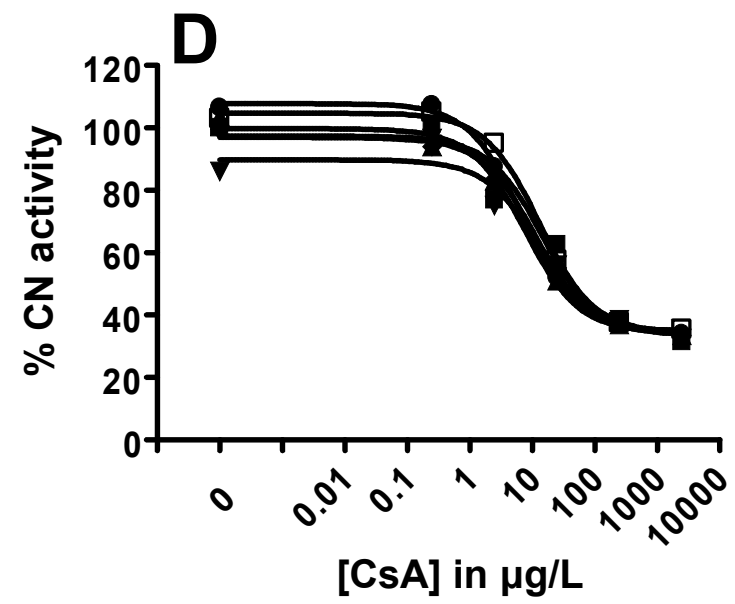

- $0 \mu \mathrm{g} / \mathrm{L} \mathrm{EVL}$

$\Delta 0.25 \mu \mathrm{g} / \mathrm{L} \mathrm{EVL}$

> $2.5 \mu \mathrm{g} / \mathrm{LEVL}$

- $25 \mu \mathrm{g} / \mathrm{L} E V L$

- $250 \mu \mathrm{g} / \mathrm{L} E V \mathrm{~L}$

口 $2500 \mu \mathrm{g} / \mathrm{L} E V L$

- $0 \mu \mathrm{g} / \mathrm{LEVL}$

$\Delta 0.25 \mu \mathrm{g} / \mathrm{L} \mathrm{EVL}$

$\checkmark 2.5 \mu \mathrm{g} / \mathrm{L} \mathrm{EVL}$

- $25 \mu \mathrm{g} / \mathrm{L}$ EVL

- $250 \mu \mathrm{g} / \mathrm{L} E V \mathrm{~L}$

$2500 \mu \mathrm{g} / \mathrm{L} E V L$ 

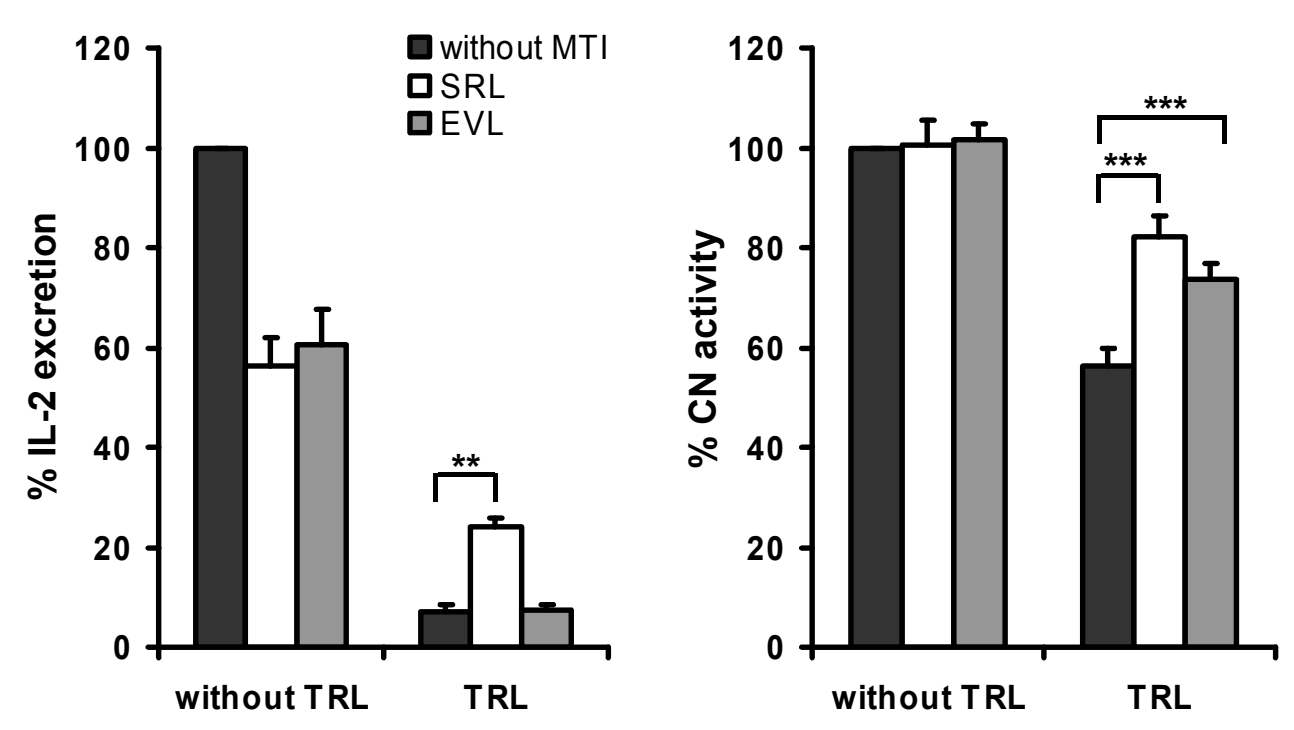


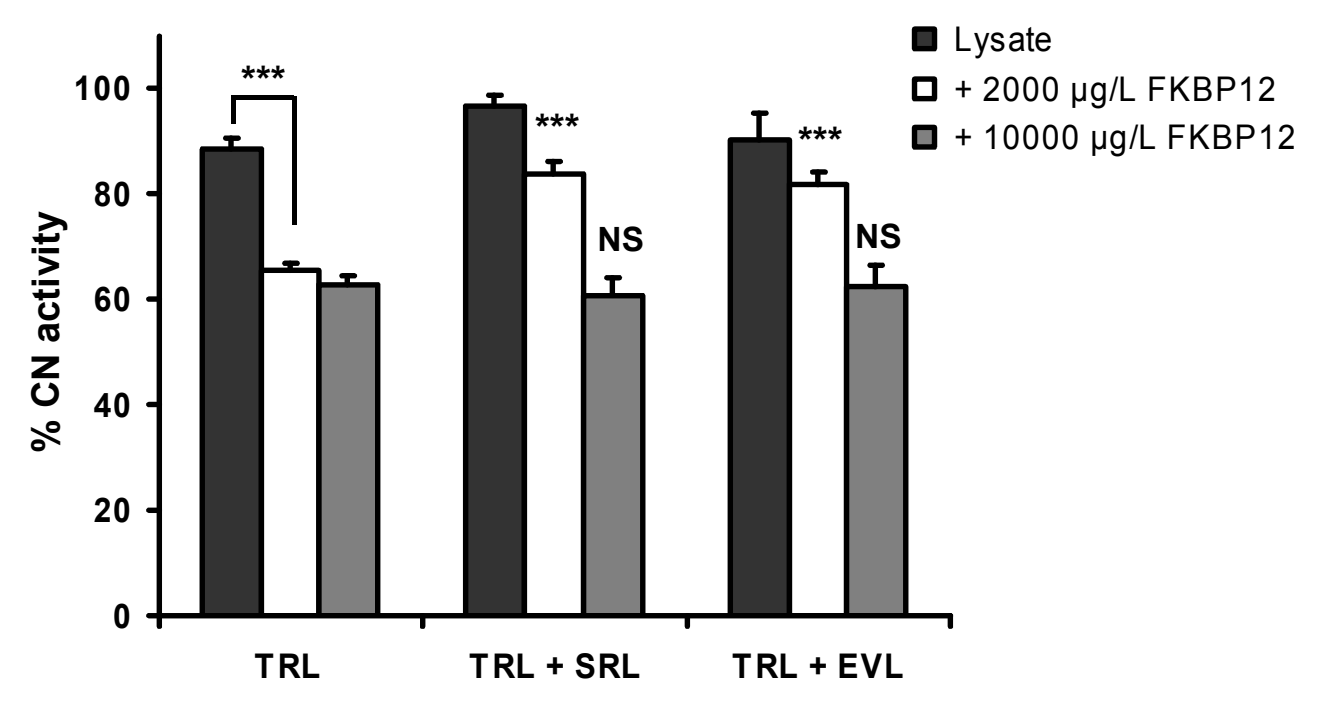




\section{Graphical abstract}
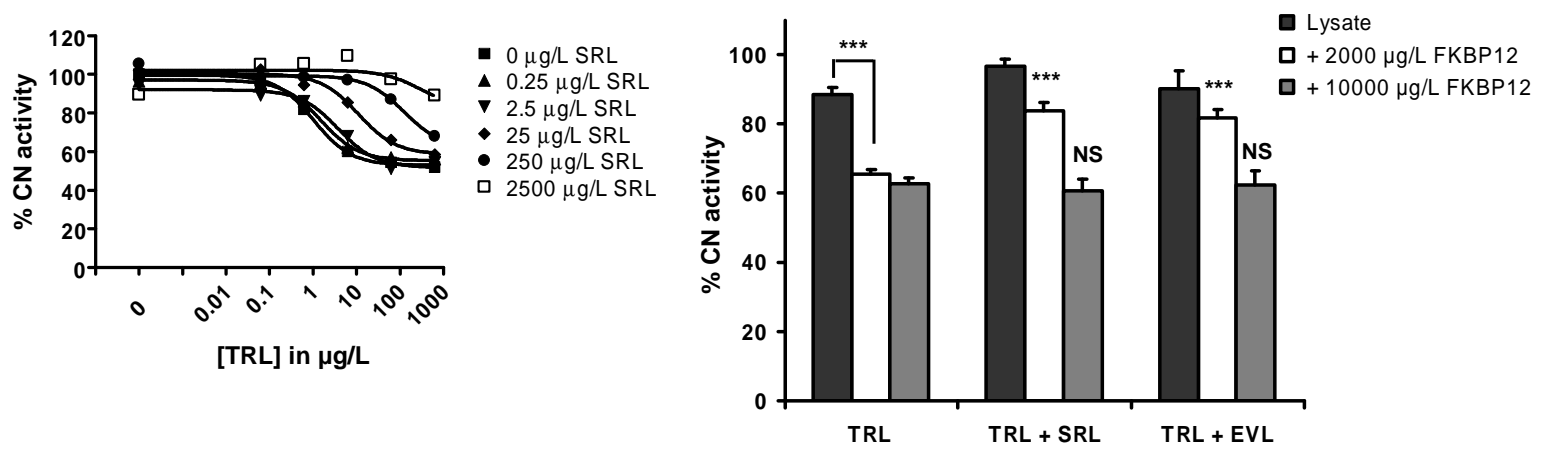